\title{
Ancient origin of somatic and visceral neurons
}

\author{
Marc Nomaksteinsky ${ }^{1,2}$, Stefan Kassabov ${ }^{3}$, Zoubida Chettouh ${ }^{1,2}$, Henri-Corto Stoeklé ${ }^{1,2}$, Laure Bonnaud4, \\ Gilles Fortin ${ }^{5}$, Eric R Kande $\left.\right|^{3,6,7}$ and Jean-François Brunet ${ }^{1,2^{*}}$
}

\begin{abstract}
Background: A key to understanding the evolution of the nervous system on a large phylogenetic scale is the identification of homologous neuronal types. Here, we focus this search on the sensory and motor neurons of bilaterians, exploiting their well-defined molecular signatures in vertebrates. Sensorimotor circuits in vertebrates are of two types: somatic (that sense the environment and respond by shaping bodily motions) and visceral (that sense the interior milieu and respond by regulating vital functions). These circuits differ by a small set of largely dedicated transcriptional determinants: Brn3 is expressed in many somatic sensory neurons, first and second order (among which mechanoreceptors are uniquely marked by the Brn3+//slet1+/Drgx+ signature), somatic motoneurons uniquely co-express $L h \times 3 / 4$ and $M n \times 1$, while the vast majority of neurons, sensory and motor, involved in respiration, blood circulation or digestion are molecularly defined by their expression and dependence on the panvisceral determinant Phox2b.

Results: We explore the status of the sensorimotor transcriptional code of vertebrates in mollusks, a lophotrochozoa clade that provides a rich repertoire of physiologically identified neurons. In the gastropods Lymnaea stagnalis and Aplysia californica, we show that homologues of Brn3, Drgx, Islet1, Mnx 1, Lhx3/4 and Phox2b differentially mark neurons with mechanoreceptive, locomotory and cardiorespiratory functions. Moreover, in the cephalopod Sepia officinalis, we show that Phox2 marks the stellate ganglion (in line with the respiratory — that is, visceral - ancestral role of the mantle, its target organ), while the anterior pedal ganglion, which controls the prehensile and locomotory arms, expresses Mnx.
\end{abstract}

Conclusions: Despite considerable divergence in overall neural architecture, a molecular underpinning for the functional allocation of neurons to interactions with the environment or to homeostasis was inherited from the urbilaterian ancestor by contemporary protostomes and deuterostomes.

Keywords: Sensory neurons, Motor neurons, Evolution, Transcription factors, Mollusks, Lophotrochozoa, Lymnaea, Aplysia, Sepia, Phox2, Brn3, Mnx

\section{Background}

For several decades, molecular data have been used to define homologous regions in the nervous system of distant phyla. More recently, homology search has moved to the cell level, using conserved neuronal-type specific molecular signatures [1-5] (and reference [6] for review). This approach provides a novel window on the complexity of ancestral nervous systems, and sets the stage, with unprecedented detail, for an understanding of what has changed or been conserved during their large-scale

\footnotetext{
* Correspondence: jfbrunet@biologie.ens.fr

${ }^{1}$ Institut de Biologie de l'École normale supérieure (IBENS), CNRS UMR8197, INSERM U1024, Paris, France

${ }^{2}$ Paris Sciences et Lettres University, Paris, France

Full list of author information is available at the end of the article
}

evolution. In this paper, we undertake a comparison of sensorimotor circuits across the protostome/deuterostome boundary, which is, thus, informative about the nervous system of Urbilateria.

Ever since Bichat distinguished the 'organic' and 'animal' lives [7], the vertebrate body has been construed as a dual entity, one part somatic (engaged with the outside world), the other visceral (concerned with bodily homeostasis). Paralleling this distinction, the sensorimotor circuits passing through the spinal cord and brainstem are divided into somatic and visceral. Somatic circuits are responsible for the somesthetic, visual or auditory perception of the environment and locomotory responses. The visceral circuits are responsible for sensing parameters of the interior milieu, such as arterial pressure,

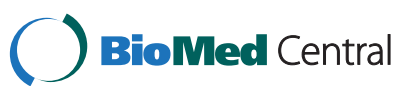


blood gases and various chemosensory modalities including taste, and feedback regulation of the cardiovascular, respiratory and digestive organs. Specific anatomic features and embryonic origins have been progressively discovered for these circuits. For example, somatic and visceral neurons in the vertebrate hindbrain are born and settle at distinct dorso-ventral levels [8]. In the peripheral nervous system, first-order visceral sensory neurons emerge from epibranchial placodes, whereas somatic ones derive from dorso-lateral placodes or the neural crest [9]. In his landmark monograph on the subject, A.S. Romer synthesized a century of observations on the 'duality' of the vertebrates, made up of two bodies (and nervous systems), one visceral and one somatic, 'imperfectly welded' on each other [10]. In the past years, after decades of neglect, the proposed dichotomy of the vertebrate nervous system has found, piecemeal, an unexpected molecular basis, in the form of transcription factors that globally distinguish somatic from visceral neurons (Figure 1) and are largely, if not completely, restricted to them. Most somatic sensory neurons, first- and second-order, express the POU domain genes Brn3: the touch and pain receptors of the dorsal root and cranial ganglia, auditory and vestibular neurons, ganglionic cells of the retina, and many relay sensory neurons of the dorsal horn of the spinal cord even if, in the latter, expression is transient and not entirely charted [11,12] (and references therein). Brn3 is required in all the peripheral cell types, its role in the central nervous system (CNS) being yet unexplored. Somatic motoneurons express and require the combination of the homeobox genes $M n x 1$ [13] and $L h x 3 / 4$ [14]. Finally, the vast majority of visceral neurons, sensory and motor, express and require the homeobox gene Phox $2 b$ : visceral sensory ganglia and their target, the nucleus of the solitary tract, all autonomic ganglia; visceral motoneurons of the medulla; branchial motoneurons (respiratory - that is, visceral - in the ancestral vertebrates) and chemosensory structures, such as the carotid body and the retrotrapezoid nucleus [12,15-17]. This simple, non-combinatorial code provides new tools to probe the ancestry of these broad neuronal categories.

For this study, we turned to mollusks, for two reasons: first, they belong to the phylum Lophotrochozoa which, genetically less derived than Ecdysozoa, is particularly valuable for comparisons across Bilateria [18]; and second, mollusks have been studied by neurophysiologists for decades and consequently provide a unique catalogue of identified neurons with somatic or visceral functions [19] that allow rigorous tests of association with specific molecular signatures. Using as model systems two gastropods - the opisthobranch Aplysia californica and the pulmonate Lymnaea stagnalis - and the decapodiform cephalopod Sepia officinalis, we show that physiologically defined somatic motor and sensory neurons and visceral motoneurons share, respectively, the $M n x / L h x 3 / 4$, Brn3 and Phox 2 transcriptional signature of their vertebrate counterparts, and we discuss the evolutionary implications of this conservation across Bilateria.

\section{Results}

\section{Shared molecular signature of gastropod and vertebrate mechanosensory neurons}

In vertebrates, the vast majority of sensory neurons that perceive the environment (with the exception of olfactory neurons) express paralogues of the POU-IV/Brn3 homeogene family, henceforth collectively called Brn3. These include mechanoreceptors, proprioceptors, thermoreceptors and nociceptors of the dorsal root and trigeminal ganglia, retinal ganglion cells, vestibular and cochlear sensory neurons and inner hair cells [11] (and references therein), as well as many second-order neurons in these somatic sensory pathways [12] (and references therein). The evolutionary stability of this genetic signature across Bilateria has been uncertain so far, based on the study of model ecdysozoans: mechanoreceptors have not been reported to express the orthologue of Brn3 in Drosophila, where it labels olfactory neurons instead [20], and they form only a small fraction of the 57 neurons that express the Brn3 orthologue in Caenorhabditis elegans [21]. In the gastropod Haliotis asinina, expression of Brn3 in patches of larval ectoderm has been interpreted as marking peripheral sensory structures [22]. We examined the case of $A$. californica, where mechanoreception and nociception are mediated, at least in part, by clusters of small-size sensory neurons in several ganglia of the CNS, which synthesize the neuropeptide sensorin A [23]. We cloned the Aplysia orthologue of Brn3 [see Additional file 1: Figure S1a] and found it expressed in the Sensorin ${ }^{+}$neuronal clusters and restricted to them in the $\mathrm{CNS}$ (Figure $2 \mathrm{a}-\mathrm{d}, \mathrm{q}$ for the pleural and cerebral clusters). In another gastropod, the pulmonate L. stagnalis, similar clusters of small Brn $3^{+}$ neurons occurred in several ganglia (Figure $2 \mathrm{e}$ for the pleural ganglion), many of which expressed the Lymnaea orthologue of Sensorin (Figure $2 \mathrm{f}$ and Additional file 1: Figure S2) and are thus most likely homologous to the mechanoreceptors of Aplysia. To further elucidate the molecular signature of these cells, we cloned the Lymnaea orthologues of Drgx [see Additional file 1: Figure $\mathrm{S} 1 \mathrm{~b}]$, largely restricted to sensory neurons in vertebrates [24], and of Islet1 [see Additional file 1: Figure S1c], expressed in all vertebrate sensory neurons [25] (and motoneurons). Both were coexpressed with Brn3 in Lymnaea (Figure $2 \mathrm{~g}$-j,r) as is the case for their orthologue in the touch and pain receptors of the mammalian dorsal root ganglia (Figure 2m-o,s). In addition, Lymnaea sensory clusters, like their vertebrate counterparts, expressed the 


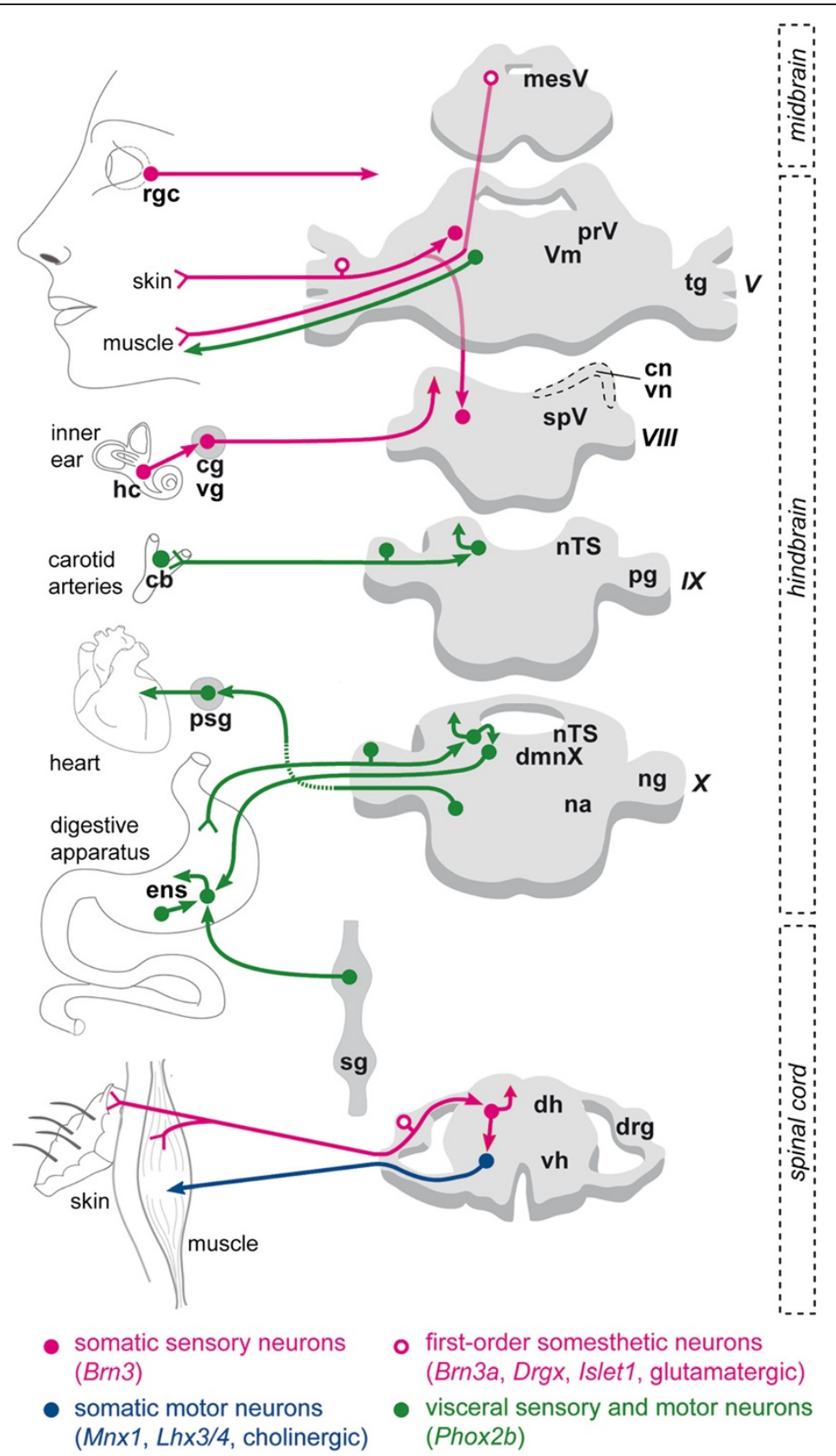

Figure 1 Somatic and visceral neurons are distinguished by a small set of transcription factors in vertebrates. Schematic of the main neuronal types that form the sensorimotor circuits in vertebrates, and their molecular code. An exemplar of each category is shown with its target organ. Magenta: somatic sensory neurons (with a history of Brn3 expression), including somesthetic neurons (mechanoreceptors, proprioceptors, thermoreceptors and nociceptors) of the trigeminal and dorsal root ganglia, and at least some of their post-synaptic partners in the nuclei of the trigeminal nerve and dorsal horn of the spinal cord, respectively, retinal ganglionic cells and vestibulo-cochlear neurons, and the latters' targets, the hair cells of the inner ear. Blue: somatic motoneurons (with a history of Mnx 1 and Lhx3/4 expression) that control bodily motions. Green: neurons of the visceral sensory pathways and motor outflow (with a history of Phox2b expression): first-order sensory neurons in epibranchial ganglia and second-order sensory neurons of the nTS; the carotid body; sympathetic, parasympathetic and enteric ganglionic neurons, and preganglionic neurons to the latter two; and branchiomotor neurons (respiratory in aquatic vertebrates). V, trigeminal nerve; Vm, motor nucleus of the trigeminal nerve; VIII, vestibulo-cochlear nerve; IX, glossopharyngeal nerve; $\mathrm{X}$, vagal nerve; cb, carotid body; cg, cochlear ganglion; $\mathrm{cn}$, cochlear nuclei; dh, dorsal horn; $\mathrm{dmnX}$, dorsal motor nucleus of the vagus nerve; drg, dorsal root ganglion; hc, cochlear and vestibular hair cells; ens, enteric nervous system; mesV, mesencephalic nucleus of the trigeminal nerve; na, nucleus ambiguus; ng, nodose ganglion; nTS, nucleus of the solitary tract; pg, petrosal ganglion; prV, principal nucleus of the trigeminal nerve; psg, parasympathetic ganglion; rgc, retinal ganglion cells; sg, sympathetic ganglia; spV, spinal nucleus of the trigeminal nerve; tg, trigeminal ganglion; vg, vestibular ganglion; vh, ventral horn; vn, vestibular nuclei. 

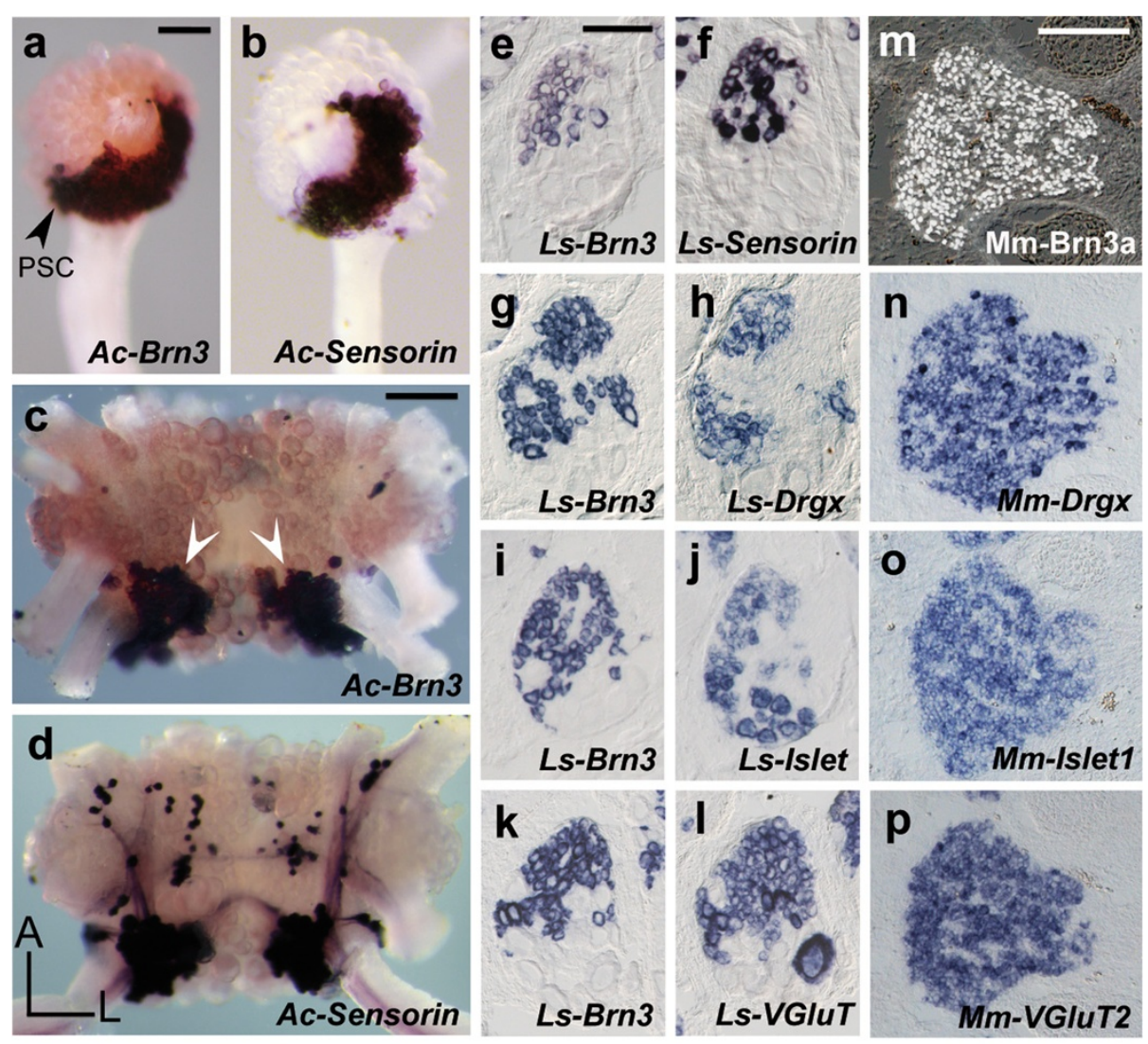

q

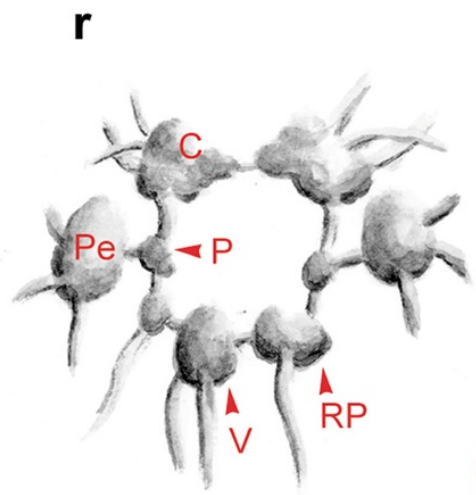

$\mathbf{S}$
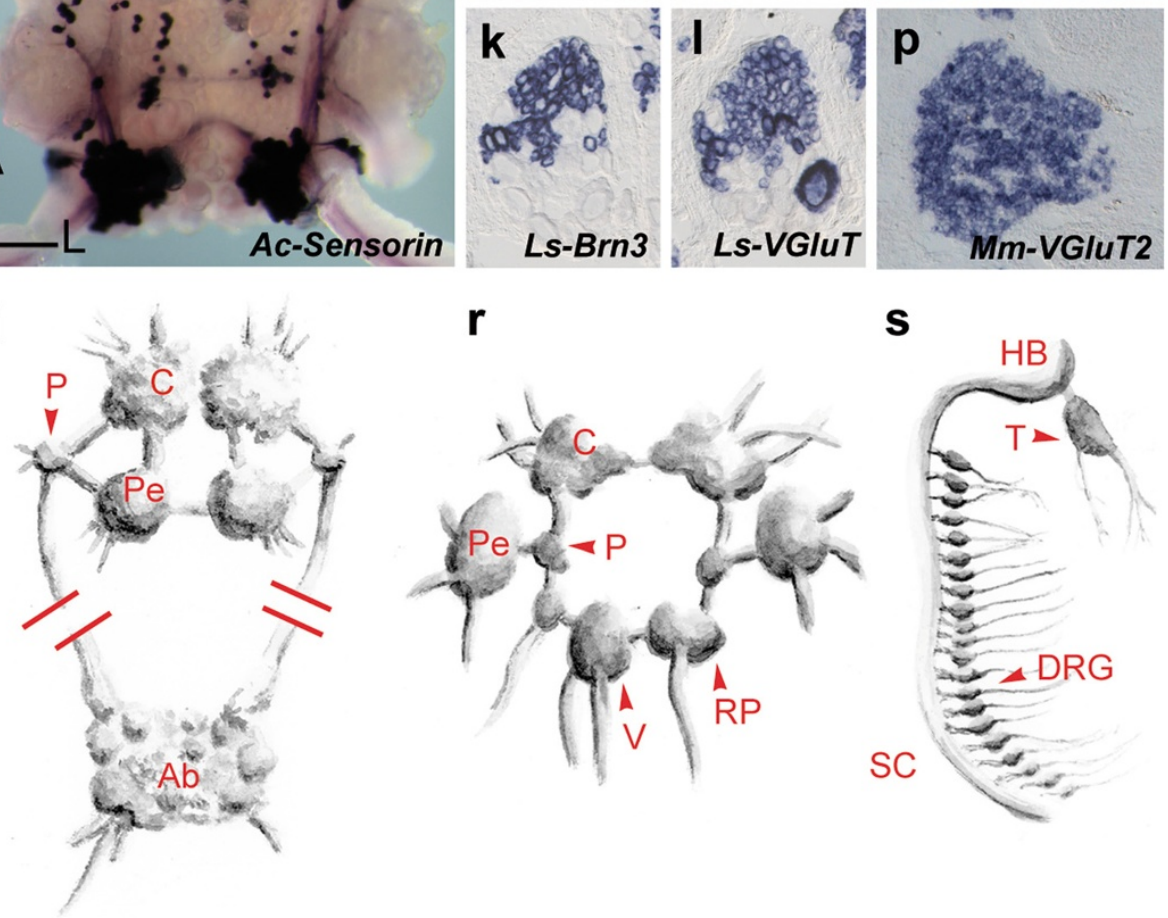

Figure 2 Transcriptional code of mechanoreceptors in gastropods and vertebrates. (a-d) Whole-mounts of the pleural (a,b) or cerebral ganglion (c,d) (ventral view) of Aplysia californica (Ac) hybridized with the indicated probes. In the cerebral ganglia, Brn3 is expressed in the Sensorin $^{+} \mathrm{J}$ and $\mathrm{K}$ sensory clusters (white arrowheads) [23] but not in the scattered Sensorin ${ }^{+}$cells. Projections from the sensory clusters contain the Sensorin mRNA and are detected by in situ hybridization [23]. (e-l) Consecutive sagittal sections of the pleural ganglion of Lymnaea stagnalis (Ls) showing coexpression of the indicated genes. ( $\mathbf{m}-\mathbf{p})$ Consecutive sagittal sections of a dorsal root ganglion in Mus musculus (Mm) showing coexpression of the indicated genes. In Lymnaea pleural ganglia, Islet and VGluT are also expressed in large Brn3- neurons at the ventral pole. (q-s): schematic of the nervous system of Aplysia californica (q), Lymnaea stagnalis (r) and Mus musculus (s). A, anterior; Ab, abdominal ganglion; C, cerebral ganglion; DRG, dorsal root ganglion; HB, hindbrain; L, left; P, pleural ganglion; Pe, pedal ganglion; PSC, pleural sensory cluster; RP, right parietal ganglion; SC, spinal cord; T, trigeminal ganglion; V, visceral ganglion. Scale bars, $100 \mu \mathrm{m}(\mathrm{a}, \mathrm{b}) ; 200 \mu \mathrm{m}(\mathrm{c}, \mathrm{d}) ; 100 \mu \mathrm{m}(\mathrm{e}, \mathrm{g}, \mathrm{i}, \mathrm{k}) ; 100 \mu \mathrm{m}(\mathrm{f}, \mathrm{h}, \mathrm{j}, \mathrm{l})$; $200 \mu \mathrm{m}(\mathrm{m}-\mathrm{p})$. 
vesicular glutamate transporter VGluT (Figure $2 \mathrm{k}, \mathrm{l}, \mathrm{p}$ ), in line with the glutamatergic phenotype of molluscan mechanoreceptors [26]. Thus, the unique Brn $^{+} / \operatorname{Drgx}^{+} /$Islet $^{+} /$VGluT $T^{+}$ transcriptional signature of first-order somatic sensory neurons in vertebrates, is also a hallmark of their molluscan counterparts.

\section{Shared molecular distinction between somatic and visceral motoneurons in gastropods, cephalopods and vertebrates}

In vertebrates, locomotion depends on somitic muscles, innervated by spinal cord motoneurons that depend on the homeogenes $M n x 1$ [13] and $L h x 3 / 4$ [14] and use acetylcholine as neurotransmitter. In gastropods, the muscles of locomotion (in the foot and body wall or attached to the columella) are innervated by the pedal ganglia [27]. We cloned Ls-Mnx, the Lymnaea orthologue of $M n x 1$ [see Additional file 1: Figure S1d] and found that it was largely restricted to two clusters of neurons in the pedal ganglia (Figure 3a), which coexpressed the orthologues of $L h \times 3 / 4$ (Figure $3 c$ and Additional file 1: Figure S1e) and the vesicular acetylcholine transporter VAChT (Figure 3b,d). At least some of these cells projected in the pedal nerves, as assessed by retrograde filling (Figure $3 \mathrm{e}-\mathrm{g}$ ) and most likely are locomotory neurons. These data extend the observations that some motoneurons in Drosophila also express Lim3 (the $L h x 3 / 4$ orthologue) and $M n x[28,29]$, that some $C$. elegans motoneurons express a $M n x$ orthologue [30], and that the $N k x 6^{+}$domain of the annelid nerve cord gives rise to $M n x^{+} / V A C h T^{+}$putative motoneurons [31]. Thus, the $M n x^{+} / L h x 3 / 4^{+}$molecular signature has been associated with somatic motoneurons since the origin of bilaterians.

We next examined the visceral nervous system, whose sensorimotor circuits in vertebrates largely coincide with the expression pattern of the paralogous homeogenes Phox $2 a$ and Phox $2 b$ (hereafter collectively designated as Phox2) and depend on the latter for their formation [12,15-17]. Among deuterostomes, we previously found that the Ciona intestinalis orthologue of Phox2 is specifically expressed in neurons of the cerebral ganglion of postmetamorphic animals that motorize the respiratory and digestive 'branchial basket' [2]. Concerning protostomes, the C. elegans orthologue of Phox 2 marks specifically five neurons [32] whose function is either unknown (the SIAs) or hard to classify as somatic or visceral (ALA, involved in behavioral quiescence [33]). The inconclusiveness of the latter finding is compounded by the fact that most visceral organs in C. elegans either lack innervation (such as the intestine) or are missing altogether (such as a cardiovascular or a respiratory apparatus). In $A$. californica, several neurons with cardiovascular, respiratory or excretory functions have been
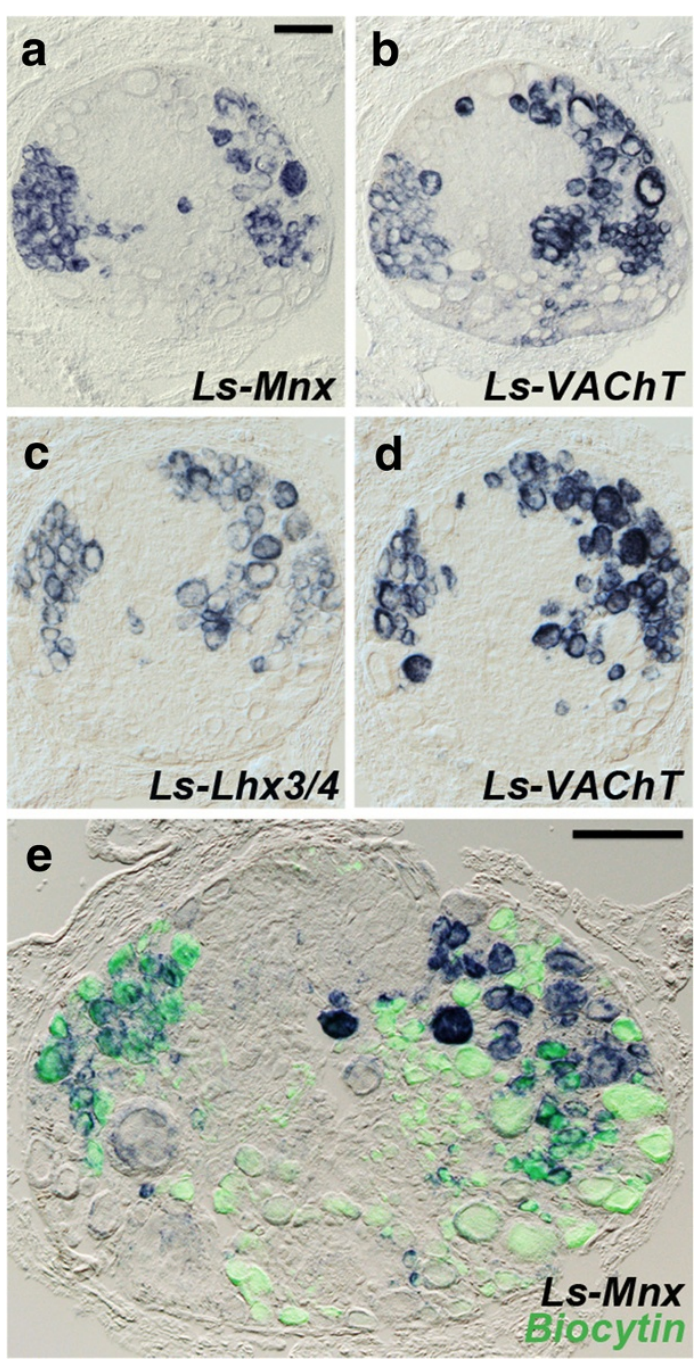

Figure 3 Transcriptional code of putative somatic motoneurons in the pedal ganglia of Lymnaea stagnalis. Consecutive sagittal sections (respectively $\mathbf{a}, \mathbf{b}$ and $\mathbf{c}, \mathbf{d}$ ) through the pedal ganglion hybridized with the indicated probes. In e, the ganglion was hybridized with $L s-M n x$ after retrograde filling with biocytin through the three pedal nerves to the foot. The three nerves to the neck and columella, also involved in locomotion, were not filled. The anterior cluster of $\mathrm{Mnx}^{+}$cells is filled, as well as about half of the posterior cluster. Scale bars, $100 \mu \mathrm{m}$.

identified by size and location in the abdominal ganglion. One of the best documented, the multimodal motoneuron L7, directly innervates the muscles of the gill, siphon, epineural sheath, heart and abdominal aorta [34] (and references therein), and serves as premotor neuron for the branchial ganglion [35]. We cloned Ac-Phox2, the Aplysia orthologue of Phox2 [see Additional file 1: Figure S1b] and found it expressed in L7, recognizable by its large size and position at the left border of the abdominal ganglion, rostral to the other large (and also $\mathrm{Phox}^{+}$) neuron in the region, L11, which projects in the genital nerve but whose function is 
unknown (Figures 4a,b and 2q). Among the other neurons expressing Phox2 was a large cluster occupying the 'right upper quadrant' of the ganglion (Figure 4a,b), which includes the giant R3-R13 cells [36] that innervate the heart, major arteries and veins, digestive gland sheath and kidney [37]. Many neurons that are smaller than the R3-R13 cells were also positive for Phox2 in this region. These might correspond to the extra cells found to share with R3-R13 electrical activity [38], immunoreactivity for the cardiomodulator peptide NdWFamide [39] and, thus, possibly a function. A giant Phox $2^{+}$cell located close to the branchial nerve corresponded to R14 (Figure 4a), which shares its targets with the R3-R13 group [37]. The R3-R14 neurons are thought to modulate heart beat frequency and local aspects of circulatory physiology using, among others, the peptide HRBP [40] as neurotransmitter. The kidney also receives input from giant neurons of the 'left upper quadrant'. Among those, L5 is uniquely identified by expression of the peptide encoding the LUQ-1 gene [41], allowing us to show on consecutive sections that it was Phox $2^{+}$(Figure 4c,d). In Lymnaea, large 'Light Yellow Cells' (LYCs) [42] are considered homologous to the R3-R14 neurons on the basis of their size, color, location, synthesis of a peptide similar to HRBP [43] and projections to the heart, aorta, kidney, and connective tissue of the CNS [44]. We cloned Lymnaea Phox2 [see Additional file 1: Figure S1b] and found that it was expressed in all LYCs of the ventrolateral lobe of the right parietal ganglion, identified by their position and expression of the $L Y C$ pro-peptide (Figures 4e,f and 2r). Retrograde filling showed that they projected in the right parietal nerves (Figure 4g), which innervate the mantle cavity and pneumostome [45], suggesting an additional role in ventilation.

As a further test of the vertebrate-like molecular signature of visceral and somatic motoneurons in mollusks, we explored a second molluscan clade, Cephalopoda. In decapodiform cephalopods (squid and cuttlefish), the brachial ganglion and anterior part of the pedal ganglion contain motoneurons for the prehensile and locomotory arms, while the palliovisceral ganglion contains motoneurons for the visceral mass [46,47]. We cloned the orthologues of $M n x$ and Phox 2 in S. officinalis [See Additional file 1: Figure S1b,d] and found that $M n x$, but not Phox2, was expressed throughout the anterior pedal lobe (Figure 5a-c) while Phox2, but not $M n x$, was expressed in the palliovisceral ganglion (Figure 5a-c). Some of the palliovisceral ganglionic neurons are presynaptic to the motoneurons of the mantle, which make up most of the stellate ganglion, a synapomorphy of this clade. Phox2, but not $M n x$, was expressed in most stellate ganglionic neurons (Figure $5 \mathrm{~d}-\mathrm{f}$ ). Thus, mantle motoneurons, which control water flow over the gills, express Phox2, like the branchial motoneurons that perform the same function in fish [16,48]. Apart from their respiratory function, motoneurons to the mantle (whose axons fuse to form the so-called 'giant nerve fibers'- reference 49 and Figure $5 \mathrm{~g}$ ) allow rapid water ejection and jet-propulsion of

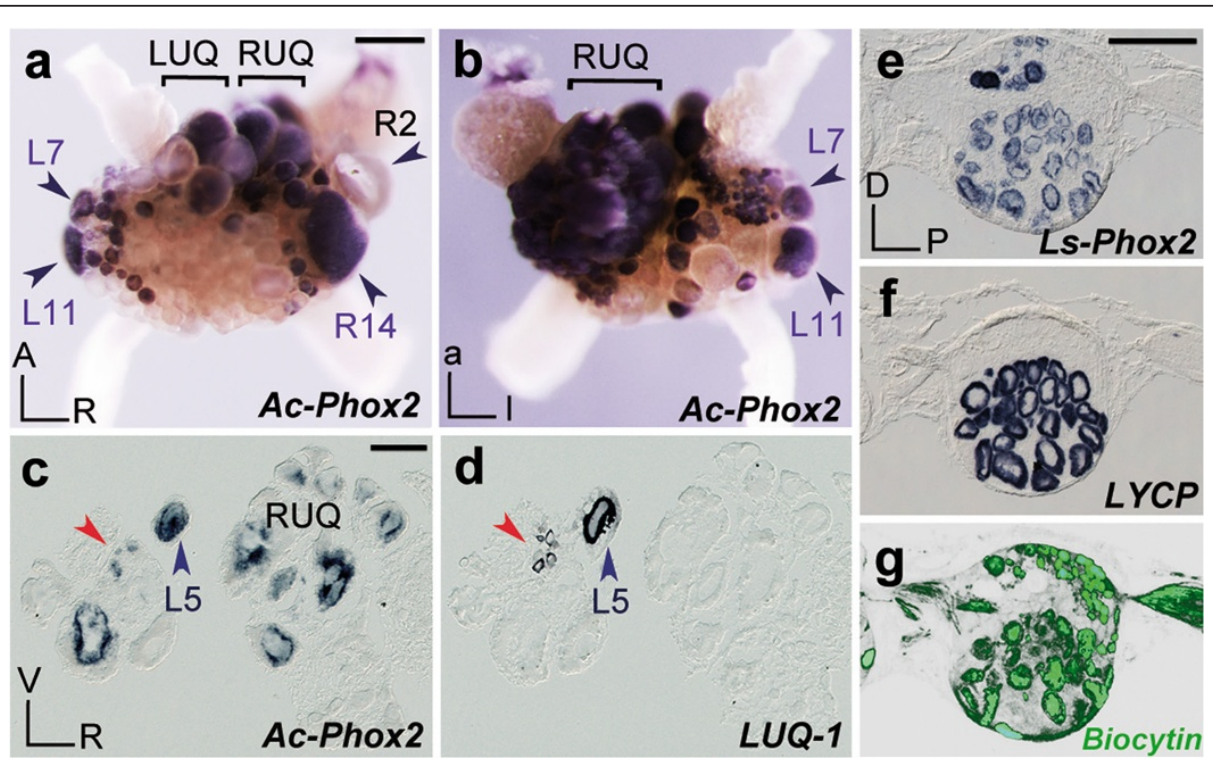

Figure 4 Expression of Phox 2 in identified visceral motoneurons in gastropods. (a-d) Abdominal ganglion of A. californica hybridized on whole-mounts (a: dorsal view, b: ventral view) or transverse sections (c,d) with the indicated probes. In $\mathbf{a}$, the giant R2 neuron is unlabeled. Red arrowheads in c,d: small neurons co-expressing Phox2 and LUQ-1. (e-g) Consecutive sagittal sections of the right parietal ganglion of L. stagnalis hybridized with the indicated probes, after it was filled with biocytin through the internal and external right parietal nerves $(\mathbf{g})$. A, anterior; D, dorsal; L, left; P, posterior; LUQ, left upper quadrant; R, right; LYCP, LYC pro-peptide; RUQ: right upper quadrant; V, ventral. Scale bars, $100 \mu$ m (a,b); $100 \mu \mathrm{m}(\mathbf{c}, \mathbf{d}) ; 200 \mu \mathrm{m}(\mathrm{e}-\mathbf{g})$. 
the animal. The molecular identity of these escape motoneurons thus correlates with the ancestral function of the target organ (respiratory, that is, visceral) rather than with its additional, derived function (locomotory, that is, somatic). A conceptually similar but inverse situation can be described in terrestrial (that is, air breathing) vertebrates, whose respiratory motoneurons (projecting to the intercostal, abdominal and diaphragmatic muscles) are somatic, that is, have kept the identity matching the embryonic origin (somitic) and ancestral function (locomotory, except for the diaphragm of mammals) of their target muscles.
Hence, molluscan motoneurons that innervate the viscera are distinguished from those that innervate the locomotory muscles by the same transcriptional code (respectively Phox 2 and $M n x / L h x 3 / 4$ ) as their vertebrate counterparts.

\section{Discussion}

We have shown that molecular signatures for neurons with somatic (that is, relational) versus visceral (that is, homeostatic) functions are conserved between vertebrates and mollusks. Visceral motoneurons, (such as
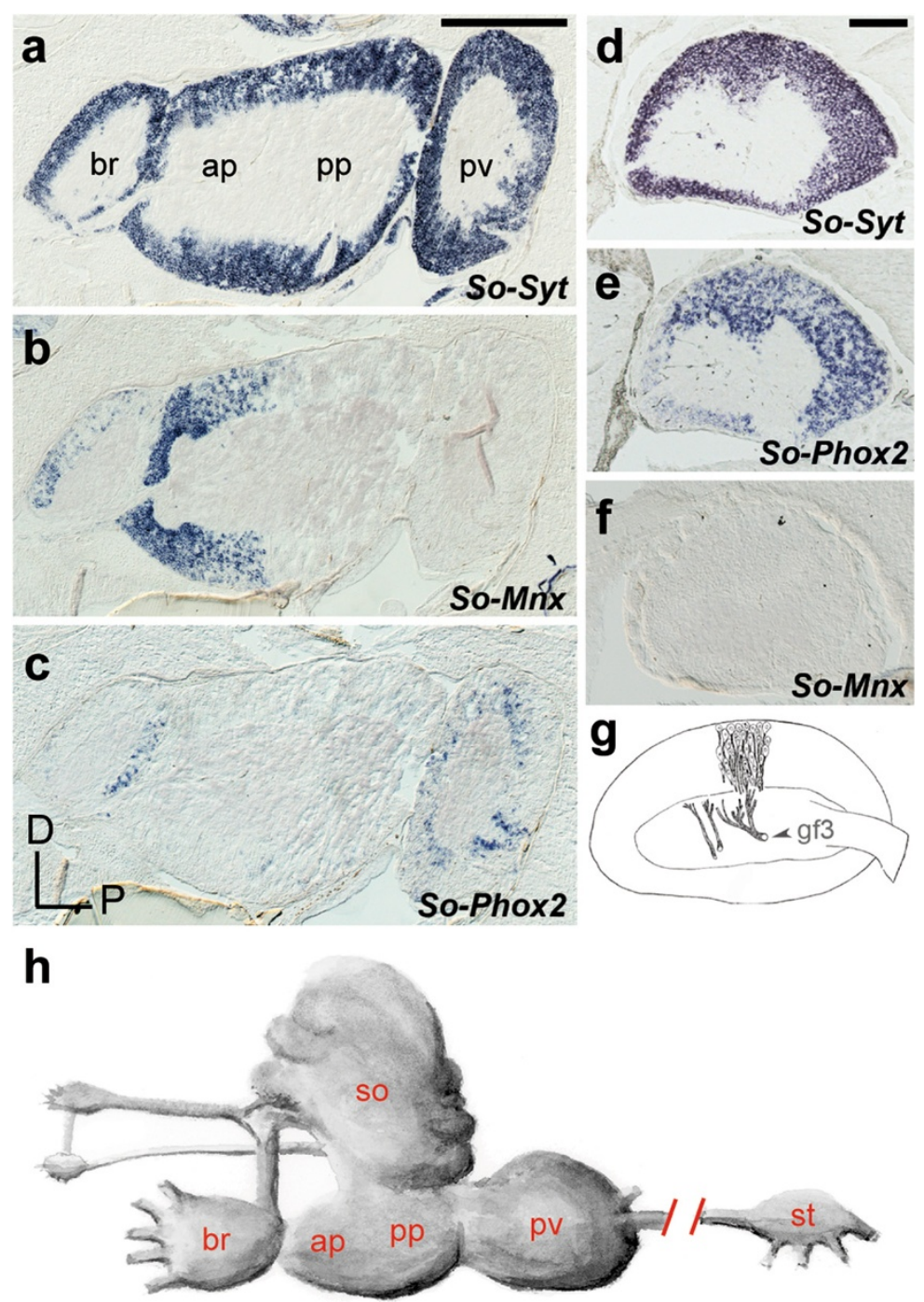

Figure 5 Expression of Phox 2 and $M n x$ in the subesophageal and stellate ganglia of Sepia officinalis. (a-f) Consecutive sagittal sections through the subesophageal ganglonic mass (a-c) or a stellate ganglion (d-f) hybridized with the indicated probes. Synaptotagmin 1/2/5 (So-Syt) is used as a pan-neuronal marker (a,d and Additional file 1: Figure S1f). Apart from the expressions described in the text, the brachial ganglion contains So-Mnx $x^{+}$neurons, in line with its role in movement of the arms, but also So-Phox2 $2^{+}$neurons in its posterior wall, whose function has not been described so far. (g) Drawing, reproduced with permission from Figure thirteen of reference [49], showing the way in which the axons of stellate ganglion neurons progressively fuse to form the third order giant fibers (gf3) that allow jet-propulsion. (h) Schematic of the central nervous system and stellate ganglion of Sepia. br, brachial ganglion; D, dorsal; $\mathrm{P}$, posterior; pa, anterior pedal ganglion; pp, posterior pedal ganglion; pv, palliovisceral ganglion; so, supraesophageal mass; st, stellate ganglion. Scale bars, $500 \mu \mathrm{m}(\mathbf{a}-\mathbf{c}) ; 200 \mu \mathrm{m}$ (d-f). 
cardiorespiratory neurons) express the orthologue of the vertebate pan-visceral determinant Phox $2 b$ in opisthobranch and pulmonate gastropods and a decapodiform cephalopod. No other transcription factor or neurotransmitter phenotype marks these neurons, specifically or exhaustively, in vertebrates, precluding a more complex signature. However, Phox $2 b$ expression is highly selective for visceral neurons (both motor and sensory) in vertebrates [16] and, thus, in combination with hodological criteria, constitutes a strong argument for homology. Neurons with modalities clearly equivalent to those of visceral sensory neurons in vertebrates (which monitor taste or blood pressure for example) are not described to our knowledge in mollusks, precluding exploration of this broad neuronal identity. Of note, in vertebrates, the viscerosensory phenotype is imposed by Phox $2 b$ on a somatosensory default identity [12], suggesting that the former is evolutionarily more recent than the latter. Locomotory (somatic) motor neurons express the orthologues of the homeobox genes $M n x 1$ and $L h \times 3 / 4$ and VAChT in both gastropods and cephalopods, like their counterparts in the spinal cord of vertebrates. Finally, somatic sensory neurons (such as mechanoreceptors), characterized in gastropods by previous electrophysiological studies or expression of the peptide sensorin A, selectively express the orthologues of the homeodomain genes Brn3, Drgx, and Islet1 and VGluT, like their physiological counterparts in the dorsal root and trigeminal ganglia of vertebrates.

What evolutionary relationship can explain the conservation of molecular signatures in neurons with visceral versus somatic functions between deuterostomes and protostomes? The simplest hypothesis is that the cells are phylogenetically homologous, that is, one could trace their ancestry to an original neuron or neuronal cluster in the common ancestor, as was proposed for ciliary photoreceptors in annelids and vertebrates [1] or for branchial motoneurons in vertebrates and urochordates [2]. This might also be the case for somatic motoneurons in vertebrates and lophotrochozoans: their distribution is spatially discrete in each phylum and reconcilable between phyla. In vertebrates, locomotory $M n x^{+}$neurons are born in a ventral $N k x 6.2^{+}$domain of the spinal cord, topologically and molecularly similar to the ventral domain of the nerve cord of annelids, which produces $M n x^{+} / V A C h T^{+}$neurons, presumably motor [31]. In mollusks, they are restricted to the pedal ganglia, conceivably homologous to the ventral nerve cord of annelids.

On the other hand, phylogenetic homology between vertebrates and mollusks is unlikely, at least in most cases, for somatic sensory neurons and visceral motor neurons, due to their anatomical distribution, widespread in each species (Figures 1, 3, 4) and hard to reconcile between them. Moreover, Phox 2 is expressed in synapomorphic structures of vertebrates (the neural crest-derived autonomic ganglia) and cephalopods (the stellate ganglion). In this case, the most likely evolutionary scenario is that, in the last common ancestor, a 'seminal regulatory interaction' [50] arose between Brn3 and the somatic sensory phenotype and between Phox 2 and the visceral phenotype. Although no target gene has been uncovered yet that would explain the physiological dichotomy these transcription factors specify, one can hypothesize, for example, that they direct axonal projections towards somatic versus visceral targets. Subsequently, this regulatory interaction would have been conserved, while Brn3 and Phox 2 acquired additional expression sites, giving rise to novel groups of cells of the same broad type along each evolutionary lineage. According to this view, the relationship between the different kinds of somatosensory neurons or visceromotor neurons would be neither of phylogenetic homology (between species) nor of 'sister cell types' (within a species [6]), but instead, both between and within species, of 'deep' [51,52] or 'generative' [53] homology, akin to that proposed for bilaterian appendages.

\section{Conclusions}

Regardless of the exact nature of what has been conserved across the protostome-deuterostome boundary, either neuronal groups or regulatory links between transcription factors and neuronal traits, our data show that the viscerosomatic duality of the nervous system, as described in vertebrates, was already part of the urbilaterian body plan. Some of its components might be even more ancient, as suggested by expression of a Brn3 orthologue in the sensory 'rhopalia' of scyphozoan and cubozoan jellyfish [54]. To our knowledge, $M n x$ has not been analyzed in the nervous system of cnidarians. Finally, no straightforward orthologue of Phox2 emerges from sequence analysis of paired-like homeobox genes in Cnidaria [see Additional file 1: Figure S1b], which complicates the search for a pre-bilaterian origin of the visceral nervous system.

\section{Methods}

\section{Tissue processing}

Ganglia from adult $A$. californica (100 to $150 \mathrm{~g}$ ) were dissected in artificial seawater $(460 \mathrm{mM} \mathrm{NaCl}, 10 \mathrm{mM}$ $\mathrm{KCl}, 55 \mathrm{mM} \mathrm{MgCl}, 11 \mathrm{mM}, \mathrm{CaCl}_{2}, 10 \mathrm{mM}$ (4-(2hydroxyethyl)-1-piperazineethanesulfonic acid (HEPES), $\mathrm{pH}$ 7.6), protease digested for two hours at $37^{\circ} \mathrm{C}$, fixed with $4 \%$ paraformaldehyde (4\% PFA) in phosphate buffered saline (PBS) overnight at $4^{\circ} \mathrm{C}$, desheathed and dehydrated in ethanol. S. officinalis fertilized eggs were removed from their envelopes in artificial seawater and fixed overnight with 4\% PFA when they reached stage 29 [55], dechorionated, fixed again with 4\% PFA for a whole day and dehydrated in methanol. Samples destined to be 
sectioned were rehydrated in PBST (PBS, 0.1\% Tween20 ), incubated overnight at $4^{\circ} \mathrm{C}$ in (PBS, $15 \%$ sucrose), incubated for 50 minutes at $65^{\circ} \mathrm{C}$ in gelatine (PBS, $7.5 \%$ gelatine, $15 \%$ sucrose, $\mathrm{pH} 7.2$ ), embedded in gelatine, frozen for one minute at $-50^{\circ} \mathrm{C}$ in isopentane and kept at $-80^{\circ} \mathrm{C}$ until sectioning. Ganglia from adult L. stagnalis (20 to $40 \mathrm{~mm}$ ) specimens were dissected in a physiological solution (40 mM NaCl, $1.7 \mathrm{mM} \mathrm{KCl,} 1.5 \mathrm{mM} \mathrm{MgCl}$, 4.1 $\mathrm{mM} \mathrm{CaCl} 2,10 \mathrm{mM} \mathrm{HEPES}, \mathrm{pH} 7.9$ ), fixed with 4\% PFA and processed for gelatine embedding as described above. cDNA from Rattus norvegicus Drgx, $R$. norvegicus Islet1 and $R$. norvegicus VGluT2 sequences and a mouse antiBrn3a monoclonal antibody (MAB1585 Millipore, Billerica, MA, USA) were used for mice procedures.

\section{In situ hybridization on sections}

Frozen sections $(12 \mu \mathrm{m})$ were thawed and air dried, washed briefly in PBST, treated $2 \times 10$ minutes with RIPA buffer (150 mM NaCl, 1\% NP-40, 0.5\% Na deoxycholate, $0.1 \%$ SDS, $1 \mathrm{mM}$ ethylenediaminetetraacetic acid (EDTA), $50 \mathrm{mM}$ Tris $\mathrm{pH} 8.0$ ), postfixed with 4\% PFA for $15 \mathrm{mi}$ nutes, washed $3 \times 5$ minutes in PBST, acetylated with (100 mM triethanolamine, $\mathrm{pH} 8.0,0.25 \%$ acetic anhydride) for 15 minutes on a rocker table and washed $3 \times 5$ minutes in PBST. Endogenous alkaline phosphatases were inactivated by a 60 -minute incubation in PBS at $80^{\circ} \mathrm{C}$. The slides were then prehybridized for 60 minutes in hybridization solution (50\% formamide, 5X SSC, $5 \mathrm{X}$ Denhardt's, $500 \mu \mathrm{g} / \mathrm{mL}$ herring sperm DNA, $250 \mu \mathrm{g} / \mathrm{mL}$ yeast RNA) at $65^{\circ} \mathrm{C}$ and hybridized with the digoxigeninlabeled RNA (Roche, Penzberg, Germany) probe (500 ng/ $\mathrm{mL}$ ) overnight at the same temperature. The slides were washed twice in 50\% formamide, 2X SSC, $0.1 \%$ Tween-20) for 60 minutes and in $0.2 \mathrm{X} \mathrm{SSC}$ at $65^{\circ} \mathrm{C}$ for 60 minutes. The slides were then rinsed $3 \times 10$ minutes in buffer 1 (100 mM maleic acid, pH 7.5, $150 \mathrm{mM} \mathrm{NaCl}, 0.1 \%$ Tween-20), blocked in buffer 2 (buffer 1, 10\% sheep serum) for 60 minutes and incubated overnight at $4^{\circ} \mathrm{C}$ with alkaline phosphatase-coupled anti-DIG antibody (Roche) diluted $1 / 2000$ in buffer 2 . The slides were washed $2 \times 10$ minutes in buffer 1 , incubated for $30 \mathrm{mi}$ nutes in buffer 3 (100 mM Tris, $\mathrm{pH}$ 9.5, $100 \mathrm{mM} \mathrm{NaCl}$, $50 \mathrm{mM} \mathrm{MgCl}_{2}, 0.1 \%$ Tween-20) and the signal was revealed in filtered buffer $4(3.5 \mu \mathrm{L}$ NBT (4-nitroblue tetrazolium chloride) (Roche) $100 \mathrm{mg} / \mathrm{mL}), 3.5 \mu \mathrm{L}$ BCIP ((5-bromo-4-chloro-3-indoylphosphate) (Roche) $50 \mathrm{mg} /$ $\mathrm{mL}$ ) in buffer 3$)$. The slides were washed $3 \times 5$ minutes in PBST and then postfixed overnight with 4\% PFA, washed briefly in PBST and then either washed in water and mounted in Aquatex (Merck) or, when nerves had been retrogradely filled, treated as follows: sections were permeabilized $2 \times 10$ minutes in PBS, $0.3 \%$ Triton $\mathrm{X}-100$, blocked 20 minutes in blocking solution (PBS, $10 \%$ fetal calf serum, $0.1 \%$ Triton X-100), incubated for two hours in the dark with ExtrAvidin-fluorescein isothiocyanate (FITC, Sigma, Saint-Quentin Fallavier, France) diluted $1 / 400$ in blocking solution, washed $3 \times$ 10 minutes in PBST in the dark and mounted in Mowiol (Calbiochem, Darmstadt, Germany).

\section{In situ hybridization on whole-mounts}

The dehydrated desheathed CNS were progressively rehydrated in PBST, incubated for 20 minutes in PBS, $0.3 \%$ Triton $\mathrm{X}-100$, rinsed in PBST, permeabilized with PBST, $10 \mathrm{mg} / \mathrm{mL}$ Proteinase $\mathrm{K}$ for 60 minutes, washed $2 \times 5$ minutes in PBST, postfixed in 4\% PFA for $30 \mathrm{mi}-$ nutes, washed $2 \times 5$ minutes in PBST, incubated for 10 minutes in $100 \mathrm{mM}$ triethanolamine, $\mathrm{pH}$ 8.0, acetylated $2 \times 10$ minutes with $100 \mathrm{mM}$ triethanolamine, $\mathrm{pH} 8.0$, $0.25 \%$ acetic anhydride, washed $2 \times 5$ minutes in PBST, incubated at $80^{\circ} \mathrm{C}$ in PBS for 60 minutes, rinsed in PBST, prehybridized for 60 minutes in hybridization buffer (50\% formamide, 1.3X SSC, $5 \mathrm{mM}$ EDTA, $50 \mu \mathrm{g} / \mathrm{mL}$ yeast RNA, $2 \%$ Tween-20, $0.5 \%$ CHAPS) at $65^{\circ} \mathrm{C}$ and hybridized overnight with the probe $(200 \mathrm{ng} / \mathrm{mL})$ at the same temperature. The samples were rinsed twice and washed $2 \times 30$ minutes in prewarmed hybridization solution at $65^{\circ} \mathrm{C}$. Then they were washed for 10 minutes at room temperature in a 1:1 mixture of hybridization solution and buffer 1, 60 minutes in buffer 1, blocked $60 \mathrm{mi}$ nutes in buffer $1 / 20 \%$ FCS, incubated overnight at $4^{\circ} \mathrm{C}$ with alkaline phosphatase-coupled anti-DIG antibody (Roche) diluted $1 / 2000$ in buffer $1 / 2 \%$ FCS, rinsed three times and washed $3 \times 60$ minutes in buffer 1 , then left for two days in buffer 1 , incubated $2 \times 30$ minutes in buffer 3 , revealed in the dark with filtered NBT/BCIP (Sigma), washed in the dark $3 \times 10$ minutes with PBST, postfixed overnight with $4 \% \mathrm{PFA}$, rinsed in PBST and kept at $4^{\circ} \mathrm{C}$ in Tissue-Tek ${ }^{\circledR}$ optimal cutting temperature (O.C.T.) embedding medium (Sakura, Tokyo, Japan). Except for revelation, all steps were performed with agitation.

\section{Immunofluorescence for detection of mouse Brn3a}

Sections were dried, washed for 5 minutes in PBS, permeabilized $2 \times 10$ minutes in PBS/ $0.3 \%$ Triton $\mathrm{X}-100$, blocked for 20 minutes in blocking solution (PBS, 10\% FCS, 0.1\% Triton X-100), incubated overnight at $4^{\circ} \mathrm{C}$ with the mouse anti-Brn3a monoclonal antibody (MAB1585) diluted $1 / 200$ in blocking solution, washed $3 \times 10$ minutes in PBST, incubated for 2 hours with the fluorescent goat anti-mouse Cy3-coupled secondary antibody (115-165-003 Jackson ImmunoResearch, Newmarket, UK), washed $3 \times 10$ minutes in PBST in the dark and mounted in Mowiol (Calbiochem). The image was converted to gray scale, inverted and superimposed on a Nomarski photomicrograph in Photoshop CS3. 


\section{Cloning of orthologues}

Starting with total RNA extracted using RNeasy Lipid Tissue Mini Kit (Qiagen), fragments of newly cloned cDNAs were amplified by PCR and rapid amplification of cDNA ends-PCR (RACE-PCR) as described previously [56]. Orthology was assigned by phylogenetic analysis (see below and Additional file 1: Figure S1). Ls-VAChT and Ls-VGluT were PCR-amplified using oligonucleotides derived from the GenBank sequences (accession numbers: AF484093 and AB469850, respectively).

\section{Nerve backfilling}

The ganglia of a 20 to $40 \mathrm{~mm}$ Lymnaea stagnalis specimen were dissected in a 1:1 mixture of physiological medium with Leibovitz's L15 medium (21083-027, Life technologies, Saint Aubin, France) complemented with $50 \mathrm{U} / \mathrm{mL}$ pennicilin, $50 \mu \mathrm{g} / \mathrm{mL}$ streptomycin and at the final concentration of $0.3 \mathrm{M}$ glucose, cutting short all nerves except those of interest. The preparation was pinned at the bottom of a sylgard dish where two compartments were delineated with Vaseline, separating the ganglia from the distal part of the nerves to be backfilled. The nerve compartment was emptied, filled with distilled water $\left(\mathrm{dH}_{2} \mathrm{O}\right)$, nerves were recut and, after a 10-minute incubation, $\mathrm{dH}_{2} \mathrm{O}$ was replaced by a saturated solution of biocytin (Sigma) in $\mathrm{dH}_{2} \mathrm{O}$. After 24 hours at room temperature and in the dark, the ganglia were fixed overnight at $4{ }^{\circ} \mathrm{C}$ in $4 \% \mathrm{PFA}$ and processed for in situ hybridization and biocytin revelation using Extravidin-FITC (see above).

\section{Phylogenetic analyses}

Gene orthologies were assessed using protein sequences aligned with ClustalX2 [57] and the software PhyML [58] with 1,000 bootstrap replicates and the model suggested by ProtTest 2.4 [59]. The closest groups of homeogenes were used as outgroups [60]. Trees were drawn with Dendroscope v3.0.14 [61].

\section{Ethical approval}

Experiments on mouse embryos have been approved by The Research Ethic committee « Charles Darwin », Paris (approval number Ce5/2012/064).

\section{Additional file}

Additional file 1: Figure S1. Support for orthology assignment of the twelve sequences cloned in this study. Figure S1 shows six phylogenetic trees for genes shared among Bilateria. Figure $\mathrm{S} 2$ shows amino acid sequence alignment between the Aplysia and Lymnaea Sensorin genes.

\section{Abbreviations}

CNS: Central nervous system; EDTA: Ethylenediaminetetraacetic acid; FCS: Fetal calf serum; FITC: Fluorescein isthiocyanate; HEPES: 4-(2hydroxyethyl)-1-piperazineethanesulfonic acid; LYC: Light yellow cells;
PBS: Phosphate-buffered saline; PBST: PBS-Tween; PCR: Polymerase chain reaction; PFA: Paraformaldehyde; RACE-PCR: Rapid amplification of CDNA ends-PCR.

\section{Competing interests}

The authors declare that they have no competing interests.

\section{Authors' contributions}

MN, ZC and HCS isolated genes and performed expression studies; GF and MN performed retrograde filling experiments; SK, LB and EK provided animal tissues from Aplysia and Sepia and participated in cell identifications; MN and JFB designed the study, analyzed the data and wrote the paper. All authors read and approved the final manuscript.

\section{Acknowledgements}

We thank E. Konstantinov for technical assistance, H. Roest Crollius and R. de Rosa for advice on the phylogenetic analyses and C. Goridis for critical reading of the manuscript. This work was supported by a grant of the Agence Nationale pour la Recherche (to JFB and GF), of the Fondation pour la Recherche Médicale (to MN) and by institutional support from the Centre de la Recherche Scientifique (CNRS), Institut National de la Santé et de la Recherche Médicale (INSERM) and École normale supérieure.

\section{Author details}

'Institut de Biologie de l'École normale supérieure (IBENS), CNRS UMR8197, INSERM U1024, Paris, France. ${ }^{2}$ Paris Sciences et Lettres University, Paris, France. ${ }^{3}$ Department of Neuroscience, College of Physicians and Surgeons of Columbia University, New York, USA. ${ }^{4}$ Museum National d'Histoire Naturelle, CNRS UMR7208, Université Pierre et Marie Curie, Paris, France. ${ }^{5}$ Institut de Neurobiologie Alfred Fessard, CNRS UPR3294, 91198, Gif-sur-Yvette, France. ${ }^{6}$ Howard Hughes Medical Institute, College of Physicians and Surgeons of Columbia University, New York, USA. ${ }^{7}$ Kavli Institute for Brain Science, College of Physicians and Surgeons of Columbia University, New York, USA.

Received: 1 February 2013 Accepted: 22 March 2013

Published: 30 April 2013

\section{References}

1. Arendt D, Tessmar-Raible K, Snyman H, Dorresteijn AW, Wittbrodt J: Ciliary photoreceptors with a vertebrate-type opsin in an invertebrate brain. Science 2004, 306:869-871.

2. Dufour HD, Chettouh Z, Deyts C, de Rosa R, Goridis C, Joly JS, Brunet JF: Precraniate origin of cranial motoneurons. Proc Natl Acad Sci USA 2006 103:8727-8732.

3. Tessmar-Raible K, Raible F, Christodoulou F, Guy K, Rembold M, Hausen H, Arendt D: Conserved sensory-neurosecretory cell types in annelid and fish forebrain: insights into hypothalamus evolution. Cell 2007, 129:1389-1400.

4. Vopalensky P, Pergner J, Liegertova M, Benito-Gutierrez E, Arendt D, Kozmik $Z$ : Molecular analysis of the amphioxus frontal eye unravels the evolutionary origin of the retina and pigment cells of the vertebrate eye. Proc Natl Acad Sci USA 2012, 109:15383-15388.

5. Abitua PB, Wagner E, Navarrete IA, Levine M: Identification of a rudimentary neural crest in a non-vertebrate chordate. Nature 2012, 492:104-107.

6. Arendt $\mathrm{D}$ : The evolution of cell types in animals: emerging principles from molecular studies. Nat Rev Genet 2008, 9:868-882.

7. Bichat X: Recherches physiologiques sur la vie et la mort. Paris: Brosson et Gabon; 1802.

8. Guthrie S: Patterning and axon guidance of cranial motor neurons. Nat Rev Neurosci 2007, 8:859-871.

9. D'Amico-Martel A, Noden DM: Contributions of placodal and neural crest cells to avian cranial peripheral ganglia. Am J Anat 1983, 166:445-468.

10. Romer AS: The vertebrate as a dual animal -somatic and visceral. Evol Biol 1972, 6:121-156

11. Badea TC, Williams J, Smallwood P, Shi M, Motajo O, Nathans J: Combinatorial expression of brn3 transcription factors in somatosensory neurons: genetic and morphologic analysis. J Neurosci 2012, 32:995-1007.

12. D'Autréaux F, Coppola E, Hirsch MR, Birchmeier C, Brunet JF: Homeoprotein Phox $2 \mathrm{~b}$ commands a somatic-to-visceral switch in cranial sensory pathways. Proc Natl Acad Sci USA 2011, 108:20018-20023. 
13. Arber S, Han B, Mendelsohn M, Smith M, Jessell TM, Sockanathan S: Requirement for the homeobox gene $\mathrm{Hb} 9$ in the consolidation of motor neuron identity. Neuron 1999, 23:659-674.

14. Sharma K, Sheng HZ, Lettieri K, Li H, Karavanov A, Potter S, Westphal H, Pfaff SL: LIM homeodomain factors Lhx3 and Lhx4 assign subtype identities for motor neurons. Cell 1998, 95:817-828.

15. Pattyn A, Morin X, Cremer H, Goridis C, Brunet JF: The homeobox gene Phox $2 b$ is essential for the development of autonomic neural crest derivatives. Nature 1999, 399:366-370.

16. Brunet JF, Pattyn A: Phox2 genes - from patterning to connectivity. Curr Opin Genet Dev 2002, 12:435-440.

17. Goridis C, Dubreuil V, Thoby-Brisson M, Fortin G, Brunet JF: Phox2b, congenital central hypoventilation syndrome and the control of respiration. Semin Cell Dev Biol 2010, 21:814-822

18. Raible F, Arendt D: Metazoan evolution: some animals are more equal than others. Curr Biol 2004, 14:106-108.

19. Kandel ER: Behavioural Biology of Aplysia: Contribution to the Comparative Study of Opisthobranch Molluscs. San Francisco: WH Freeman; 1979.

20. Clyne PJ, Certel SJ, de Bruyne M, Zaslavsky L, Johnson WA, Carlson JR: The odor specificities of a subset of olfactory receptor neurons are governed by Acj6, a POU-domain transcription factor. Neuron 1999, 22:339-347.

21. Finney M, Ruvkun G: The unc- 86 gene product couples cell lineage and cell identity in C. elegans. Cell 1990, 63:895-905.

22. O'Brien EK, Degnan BM: Developmental expression of a class IV POU gene in the gastropod Haliotis asinina supports a conserved role in sensory cell development in bilaterians. Dev Genes Evol 2002, 212:394-398.

23. Brunet JF, Shapiro E, Foster SA, Kandel ER, lino Y: Identification of a peptide specific for Aplysia sensory neurons by PCR-based differential screening. Science 1991, 252:856-859.

24. Rebelo S, Reguenga C, Osório L, Pereira C, Lopes C, Lima D: DRG11 immunohistochemical expression during embryonic development in the mouse. Dev Dyn 2007, 236:2653-2660

25. Dykes IM, Tempest L, Lee SI, Turner EE: Brn3a and Islet1 act epistatically to regulate the gene expression program of sensory differentiation. J Neurosci 2011, 31:9789-9799.

26. Dale N, Kandel ER: L-glutamate may be the fast excitatory transmitter of Aplysia sensory neurons. Proc Natl Acad Sci USA 1993, 90:7163-7167.

27. Lacaze-Duthiers $H$ : Du système nerveux des mollusques gastéropodes pulmonés aquatiques et d'un nouvel organe d'innervation. Arch zool exptl et gén 1872, 1:437-700.

28. Broihier HT, Skeath JB: Drosophila homeodomain protein $\mathrm{dHb}$ directs neuronal fate via crossrepressive and cell-nonautonomous mechanisms. Neuron 2002, 35:39-50

29. Odden JP, Holbrook S, Doe CQ: Drosophila HB9 is expressed in a subset of motoneurons and interneurons, where it regulates gene expression and axon pathfinding. J Neurosci 2002, 22:9143-9149.

30. Von Stetina SE, Fox RM, Watkins KL, Starich TA, Shaw JE, Miller DM 3rd: UNC-4 represses $\mathrm{CEH}-12 / \mathrm{HB} 9$ to specify synaptic inputs to VA motor neurons in C. elegans. Genes Dev 2007, 21:332-346.

31. Denes AS, Jékely G, Steinmetz PR, Raible F, Snyman H, Prud'homme B, Ferrier DE, Balavoine G, Arendt D: Molecular architecture of annelid nerve cord supports common origin of nervous system centralization in bilateria. Cell 2007, 129:277-288.

32. Pujol N, Torregrossa P, Ewbank JJ, Brunet JF: The homeodomain protein CePHOX2/CEH-17 controls antero-posterior axonal growth in C. elegans. Development 2000, 127:3361-3371.

33. Van Buskirk C, Sternberg PW: Paired and LIM class homeodomain proteins coordinate differentiation of the C. elegans ALA neuron. Development 2010, 137:2065-2074

34. Alevizos A, Bailey $\mathrm{CH}$, Chen M, Koester J: Innervation of vascular and cardiac muscle of Aplysia by multimodal motoneuron L7. J Neurophysiol 1989, 61:1053-1063.

35. Kurokawa M, Ohsuga K, Kuwasawa K: A reexamination of the synaptic connection between neuron $L 7$ of the abdominal ganglion and neurons of the branchial ganglion in Aplysia californica, A. kurodai and A. juliana. Neurosci Lett 1998, 241:49-52

36. Coggeshall RE, Kandel ER, Kupfermann I, Waziri R: A morphological and functional study on a cluster of identifiable neurosecretory cells in the abdominal ganglion of aplysia californica. J Cell Biol 1966, 31:363-368.
37. Rittenhouse $\mathrm{AR}$, Price $\mathrm{CH}$ : Electrophysiological and anatomical identification of the peripheral axons and target tissues of Aplysia neurons R3-14 and their status as multifunctional, multimessenger neurons. J Neurosci 1986, 6:2071-2084.

38. Frazier WT, Kandel ER, Kupfermann I, Waziri R, Coggeshall RE: Morphological and functional properties of identified neurons in the abdominal ganglion of Aplysia Californica. J Neurophysiol 1967, 30:1288-1351.

39. Morishita F, Nakanishi Y, Sasaki K, Kanemaru K, Furukawa Y, Matsushima O: Distribution of the Aplysia cardioexcitatory peptide, NdWFamide, in the central and peripheral nervous systems of Aplysia. Cell Tissue Res 2003, 312:95-111.

40. Campanelli JT, Scheller RH: Histidine-rich basic peptide: a cardioactive neuropeptide from Aplysia neurons R3-14. J Neurophysiol 1987, 57:1201-1209.

41. Landry C, Crine P, DesGroseillers L: Differential expression of neuropeptide gene mRNA within the LUQ cells of Aplysia californica. J Neurobiol 1992, 23:89-101.

42. Wendelaar Bonga SE: Ultrastructure and histochemistry of neurosecretory cells and neurohaemal areas in the pond snail Lymnaea stagnalis (L.). Z Zellforsch Mikrosk Anat 1970, 108:190-224.

43. Smit $A B$, Hoek RM, Geraerts WP: The isolation of a cDNA encoding a neuropeptide prohormone from the light yellow cells of Lymnaea stagnalis. Cell Mol Neurobiol 1993, 13:263-270.

44. Boer HH, Montagne-Wajer C: Functional morphology of the neuropeptidergic light-yellow-cell system in pulmonate snails. Cell Tissue Res 1994, 277:531-538.

45. Elo JE: Das nervensystem von limnaea stagnalis (L.) Lam. Ann Zool Soc Zool-Bot Fenn Vanamo 1938, 6:1-40.

46. Boycott BB: The functional organization of the brain of the cuttlefish sepia officinalis. Proc Roy Soc B 1961, 153:503-504

47. Young JZ: The nervous system of Loligo. II. Suboesophageal centres. Proc Roy Soc B 1976, 274:101-167.

48. Coppola E, D'Autréaux F, Nomaksteinsky M, Brunet JF: Phox2b expression in the taste centers of fish. J Comp Neurol 2012, 520:3633-3649.

49. Young JZ: Fused neurons and synaptic contacts in the giant nerve fibres of cephalopods. Phil Trans R Soc Lond B 1939, 229:465-503.

50. Scott MP: Intimations of a creature. Cell 1994, 79:1121-1124.

51. Shubin N, Tabin C, Carroll S: Fossils, genes and the evolution of animal limbs. Nature 1997, 388:639-648.

52. Shubin N, Tabin C, Carroll S: Deep homology and the origins of evolutionary novelty. Nature 2009, 457:818-823.

53. Butler $A B$, Saidel WM: Defining sameness: historical, biological, and generative homology. Bioessays 2000, 22:846-853.

54. Nakanishi N, Yuan D, Hartenstein V, Jacobs DK: Evolutionary origin of rhopalia: insights from cellular-level analyses of Otx and POU expression patterns in the developing rhopalial nervous system. Evol Dev 2010, 12:404-415

55. Lemaire J: Table de développement embryonnaire de Sepia Officinalis L. (Mollusque Céphalopode). Bull Soc Zool France 1970, 95:773-782.

56. Nomaksteinsky M, Röttinger E, Dufour HD, Chettouh Z, Lowe CJ, Martindale $\mathrm{MQ}$, Brunet JF: Centralization of the deuterostome nervous system predates chordates. Curr Biol 2009, 19:1264-1269.

57. Larkin MA, Blackshields G, Brown NP, Chenna R, McGettigan PA, McWilliam $H$, Valentin F, Wallace IM, Wilm A, Lopez R, Thompson JD, Gibson TJ, Higgins DG: Clustal W and Clustal X version 2.0. Bioinformatics 2007, 23:2947-2948

58. Guindon S, Gascuel O: A simple, fast, and accurate algorithm to estimate large phylogenies by maximum likelihood. Syst Biol 2003, 52:696-704.

59. Abascal F, Zardoya R, Posada D: ProtTest: selection of best-fit models of protein evolution. Bioinformatics 2005, 21:2104-2105.

60. Larroux C, Luke GN, Koopman P, Rokhsar DS, Shimeld SM, Degnan BM: Genesis and expansion of metazoan transcription factor gene classes. Mol Biol Evol 2008, 25:980-996.

61. Huson DH, Richter DC, Rausch C, Dezulian T, Franz M, Rupp R: Dendroscope: an interactive viewer for large phylogenetic trees. BMC Biol 2007, 8:460

doi:10.1186/1741-7007-11-53

Cite this article as: Nomaksteinsky et al:: Ancient origin of somatic and visceral neurons. BMC Biology 2013 11:53. 